fuel and labor is much higher than in the kilns, and is Magnetic Separation.-The roasted ore is spread out
computed at on a floor to cool, and separated from sintered lumps, when it is lifted by an elevator, and passed throngh a
sizing-drum to remove particles above 4 millimeters,
which are returned to the crusher, while the finer siftings pass to the electro-magnetic machines. Thes
differ materially from machines previously used for the same purpose, as they are continuous in action, while the magnets are kept out of contact with the material axis, carrying a series of electro-magnets arranged radially on a frame, covering an arc of about $90^{\circ}$ within a brass drum, nearly, but not quite, touching the magnets, which receives motion from a belt and pulley. The outer surface of the drum is made into an elevator
by a series of small ribs projecting radially. The magnets, which are so arranged that the lower series is a little below the horizontal plane, face the feedingapron, which, by an arrangement similar to that of a per in a thin stream against the excite-surface of the drum, when the magnetic particles are retained and rum, when the magnetic particles are retained and
travel upward, being kept from falling by the radial
ribs, and passing over the vertical plane fall off on the ribs, and passing over the vertical plane fall off on the
opposite side, while the blende particles, rot being attracted, fall down a shoot into a hutch in front. The separation is only approximate, and has to be repeated
upon the roughly classified product of the first opera-
tion, the ultimate products being-

1. Blende and quartz.

2. Spathic ore.

4. Mixed iron ore.

The two latter classes requiring further treatment. As the operation is attended with the production of with an exhaust-fan working continuously. Sixteen four, of which an upper pair effect the first rough separation, and deliver to the finishing pair placed
below them. The four machines in each series are excited by a Gramme dynamo of 1 horse-power; the cur-
rent is introduced at one end of the hollow axis of the drum and passes out by the other. Each of the two 24 tons of roasted ore in twelve hours, producing 7 to 8 rough stuff from the mine averages 12 to 15 per cent. zinc ore of 33 per cent., and iron, ore with 36 to 38 per cent. of iron and 10 per cent. of manganese.

Finishing Concentration.-The iron ore obtained as described is not subjected to further treatment, but the blende requires further concentration in jigging ma-
chines. For this purpose, the blende freed from iron ore is delivered by an elevator to a sizing-drum, which of which is treated on a separate jigging machine to remove earthy waste, as well as intermixed lead ore.
This gives a final salable product enriched up to 38 per cent. of zinc and lead ore, with 63 per cent. of lead, and 40 grammes of silver. The tine stuff and dust from the exhauster are treated on slime buddles, and give a
zinc product of 32 per cent., and lead ore of 65 per cent. zinc product of 32 per cent., and lead ore BAZIN'Ś ROTARY PILE.

THE agitation of the elements of a pile and the renewal of their active surfaces constitute a tho depolarization that is already very old, and from time
to time new models appear in which the inventor endeavors to utilize such action to advantage. One of lately presented by Mr. Bazin to the Societé Internationale des Electriciens, and shown in the annexed engraving. Upon an axle fixed in space are mounted two carbons. Communication between these different axle. Seven of the elements are coupled for tension, eighth element forming an insulated circuit supplies a small electric motor that serves to communicate to the axle a rotary velocity of about one revolution per

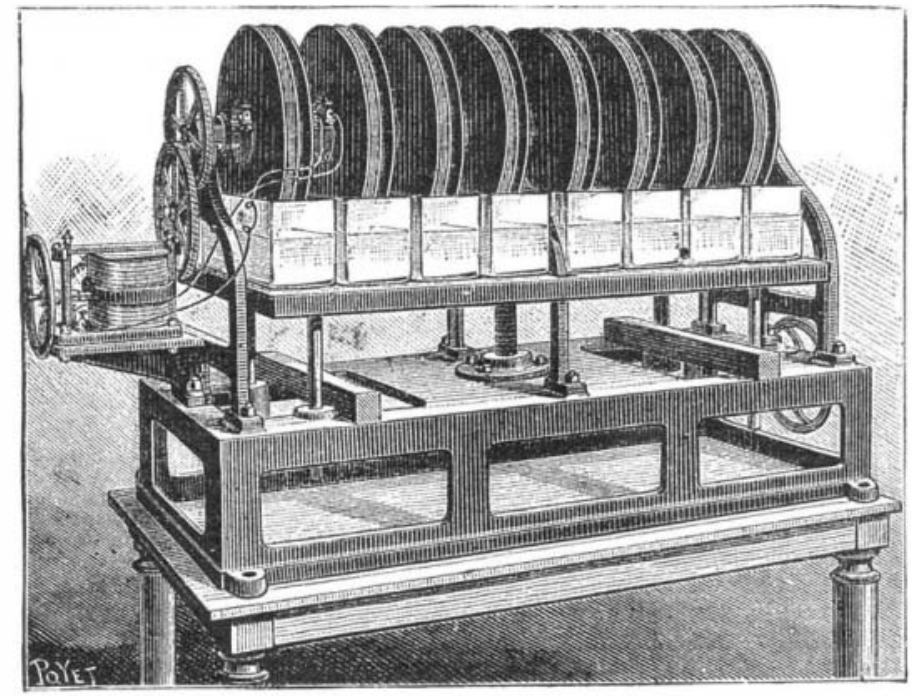

BAZIN'S ROTARY PILE.

troughs placed upon a horizontal table that may be $\mid$ quantity of electricity produced by an influence mamoved up or down by means of a screw actuated by a
hand wheel at the right of the apparatus.
the ambient gas. The continuation of these ressure of hach trough contains $5 \frac{1}{4}$ pints of a bichromate of potash solution of the following composition :

Water............ 1,000 parts by weight

$\begin{array}{lll}\text { Sulphuric acid } \ldots . . . \cdots & 300 \\ \text { Bichro. potash......... } & 125\end{array}$

We have had an opportunity of making some experi- rar's construction was selected, though the axle is
ments with this pile, and of studying its constancy placed vertically instead of horizontally The \begin{tabular}{l|l} 
ments with this pile, and of studying its constancy & placed vertically instead of horizontally. The .wxle \\
with different discharges. It has not, in our opinion & passes air-tight through an iron plate, A, and rests at
\end{tabular} \mid (up to the present, at least), answered the expectations $\mid a$ in a stuffing-box and at $b$ on a point. The motion Shown rapid decreases after but an hour's operation. The polar balls of the machine, $e$ and $f$, are fixed on

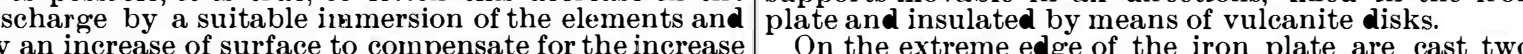
internal resistance; but frequent maneu vers like $\mid$ concentric ridges, forming a deep groove, in which the In fact, we think that a more regular operation
fitted with two cocks, $g$, and a rotation indicator, $h$, for ovable elements, on condition that a proper surface A Al the space beneath the glass bell not taken up by (n) the consider as vicious. In fact, Mr. Bazin duced into the groove of the plate, the machine is en-

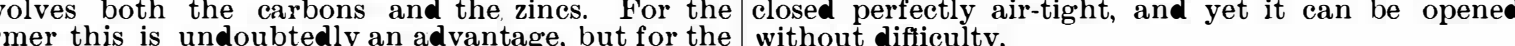
atter it is manifestly the opposite, sinee these carry
If oil of vitriol is also placed under the bell, the ma-
chine is soon surrounded by air absolutely dry and

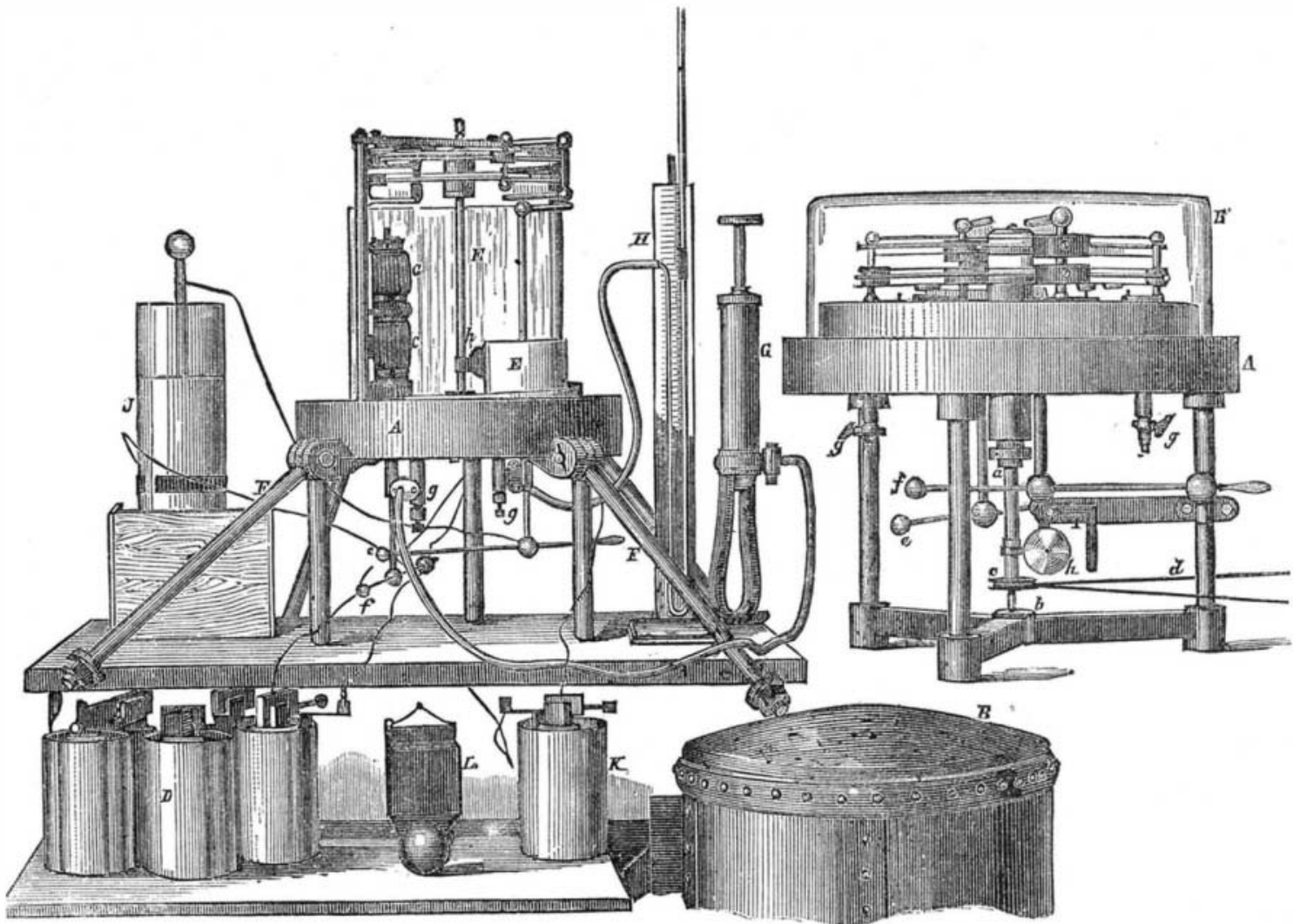

HIGH PRESSURE INFLUENCE ELECTRIC MACHINE.

is attacks them out of the liquid without producing | free from dust, which offers the great advantage that Under such circumstances the pile operates with as
the worst atmosphere of a laboratory.

zinc surface were uselessly exagomate element whose It was found that the glasses of machines thus fitted that Mr. Bazin is occupied in modifying his pile in the the zines stationary-a circumstance, moreover, that publish some figures, for those furnished by the pre-
puts wise justify the dithyrambic articles with which the
with 作 A HIGH-PRESSURE INFLUENCE ELECTRIC MACHINE.

do lacquered, so that all parts of the machine are perfectly proof against the action of the ozone which the machine generates when working
in air. We can also, without interfering with the action of the machine, use ordinary window glass which for the common construction is quite useless or the preparation of the disks, as it insulates quite As the paper coatings of the machine when perfectly ary cease to conduct electricity, they must first be rubbed over with graphite, which renders them slightly Thetive.

various vig. 2 shows the arrangement adopted for studying the action of the machine at different pressures. To render measurements possible without the disturbing effect of friction in a stuffing-box, the machine was placed on the iron plate, A, under an iron bell, B
represented in the figure as lifted off), in such a manner that the movement is effected by a small dynamo mathat the movement is effected by a small dynamo ma-
chine set in motion from without by the battery, D.
It was thus possible to keep the friction of the pegs constant at varying pressures, and to effect a really perfect closure of the space under the bell. The entire room under the bell not required for the moving parts of the bell was filled up with paraffine, $\mathbf{E}$. The iron bell was lined internally with a stratum of paraffine an
inch in thickness, and could be pressed down upon a inch in thickness, and could be pressed down upon a
caoutchouc ring laid upon the plate, A, tby means of caoutchouc ring laid upon the plate, A, by means of $g$, one of which is in connection with a forcing pump,

The conductors to the polar balls, $e, f$, were carried through the plate insulated by means of long glass standing in a box filled with melted paraffine. The Leyden jar was connected by wires with the supporters of the polar balls.

Besides, there was in the machine a revolution in dicator, $h$, connected by wires with an element, $K$, and pletion of every 100 rotations a contact took place and the bell sounded.

The connection between the dynamo and the influence machine was effected by drums and driving belts. To render it possible for the dy namoto be start-
ed in any position by simply closing the circuit, it was ed in any position by simply closing the circuit, it was dynamos were united in one. Their keepers were fixed fore and the same axle, and were so placed with remaximum of its action when the other was at the deae point. The arrangement described enables the in fuence machine under the bell to be set in motion at pleasure in different gases and under varying pressures, the revolutions of the glass disks to be counted
quantity of electricity evolved to be measured.

EXPERIMENTS WITH THE INFLUENCE MACHINE

The quantity of electricity was found by counting The number of discharges given by a Leyden jarfor the distance of the polar balls.
distanes 

The machine had lacquered disks. It appeared that $\mid$ carry about conveniently, others made to hang up by
on using hydrogen gas the corlector points of the ma- Iness to remark upon the appropriate emblem $_{\text {the }}$ the of the fireplace, a custom which continued in chine were not luminous in the dark, while in all other
gises this took place very distinctly. 1. The machine gave with hydrogen at 850 rotation
por minute 9 discharges, while in air with the same numper minute 9 discharges, while in air with the

2. In carbonic acid for 850 rotations there were in the 2. In carbonic acid for 850 rotations there were in the
at the same times, a part of the carbonic acid being at the same time converted into carbonic oxide and
ozone. 3 . The machine, further, when running at the rate of 400 rotations per minute in air at the normal pressure gave 15 discharges per minute and 32 on an increased
pressure of the atmosphere. On diminishing the pressure by half an atmosphere below the normal pressure, the Leyden jar could not be charged at all.

An attempt to obtain larger quantities of electricity by causing the machine to run under petroleum (which is a notable electric non-conductor) proved unsuccess-
ful. It is possible that by using sliding springs instead of the recipient points of the influence machine, a repetroleum insulates so well that the points are unable to transfer the electricity. old-tashioned farmhouses within the memory of man,
and which Dr. Plot, who wrote a history of Staffordshire and of Oxfordshire in the latter part of the seven have now become rare, and are met with only in muthe Bodleian library and in the Ashmolean museum at Oxford; and two in the Cheetham library at ManSomer.

Some of these are very rude, as if cut by a laboring man with his pocket knife. Some are on flat strips o which they were also called "log almanacs," "clog almanacs," clog being a provincial word of the same signification, commonly applied to the piece of wood which is tied to restive animals to prevent

There were two kinds of these almanacs; one for the
Them running a mmovable feasts, the other for the movable, with the Sundays also, and these are the most usual. When by notches on the angies, the seventh day being disusual emblems, some of which are vertivals by their Experiments show that the chemical nature of gases usual einblems, some of which are very curiously ex-
exerts on the one hand an influence on the develop-
ment of electricity by the influence machine, while on
Bodleian, the othe engravings of two, one from the the other there ensues with increasing pressure an enormous increase in the quantities of electricity pro-

of believed to be of English workmanship, but some of those in the Ashmolean are clearly Danish or Swed-
ish, having Runic (or secret) characters upon them, ish, having Runic (or secret) characters upon them, in 1681 , who stated that they were then in use among the agricultural classes in his own country. The emblems or symbols emplcyed seem to have been purely conventional, and nearly the same on all. but with the difference that instead of a glass bell ant iron cap is used, which may be fixed down air tight The above researches have been made with a Leyden jar-a rough measuring instrument-in order to obtain tric determinations of the dielectric constants of the gases at high pressures must be reserved for future inOskar Leuner, mechanician to the Dresden Poly-
technicum, has made the entire apparatus in a most
satisfactory manner.-Annalen der Physik und Che mie.

\section{CLOG ALMANACS.}

BEFORE the invention of printing, considerable difficulty was experienced in remembering the different saints' days and other holy days, and various expedients were made use of to assist the memory, the most
usual of which was a perpetual calendar, engraved on usual of which was a perpetual calendar, engraved on some hard substance, either on a large scale or a smal
one, according to circumstances. At the present day, when every cottage is supplied with its penny alma nac for the year, to be thrown aside as waste papt at
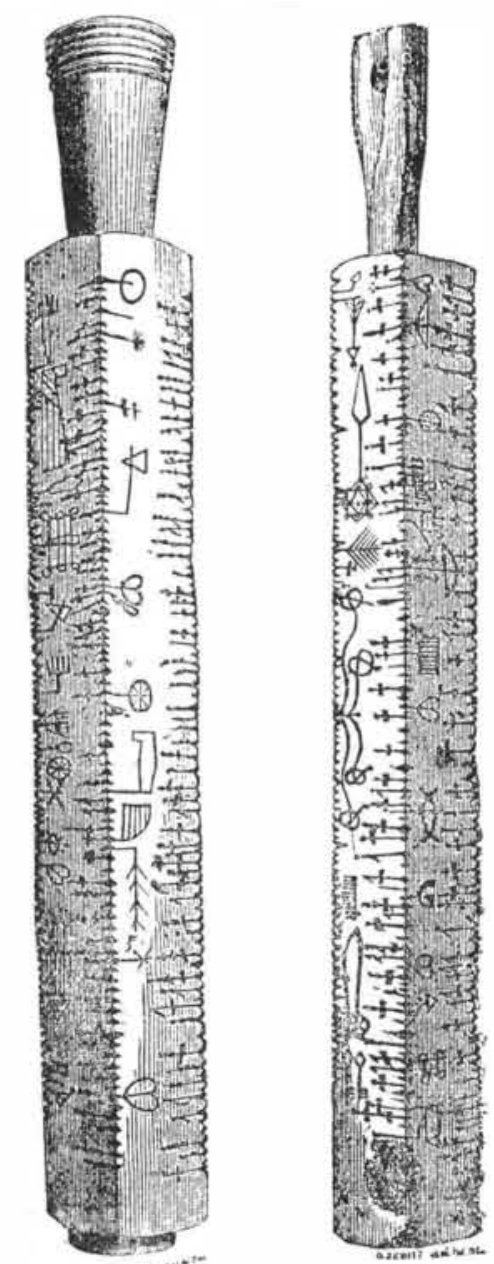

Clog Almanack.
Bodleian Library, Oxford. Ashmolean Almainack

to realize the very opposite state of things which existed in the middle ages; but the very difference makes it employed by our ancestors as a substitute for our alenoraved on a laree scale on the wall of a church. of these, as early as the twelfth century, still exists on the wall of the church of the city of Perigueux, in the south of France, and a few others of later date have been preserved. The emblems of the different seasons,
with the characteristics and the usual employment of each, are also frequently used as ornaments round the arch of a doorway, and in other situations; and they almana inums of manuscripts. Perpetual ivory, and on wood of different kinds. The most com mon are on boxwood; these are usually cut on square logs, and are often called Danish almanacs, or Runic though they were extensively used in England. These The strokes with dots on the right hand side of each cycle of the moon; if the number is under five, it is re presented by so many dots; if five, by a sloping line ine a rude $\mathrm{V}$, which stands for five If the number is above five and under ten it is marked by the number of dots on the sloping line added to five. When the number is ten, a cross stroke makes a rude $X$, which marked for ten, and the figures above ten are again prime-staves, because the prime or golden number was marked upon them. This will be more clearly underthe Prayer-book, particularly the table to find Easter, and the direction for using it, where the golden num ber or prime is mentioned.

Annexed will be found, besides the reduced sketches of the "clogs:" some of the emblems selected and drawn to the full size of the originals.
We at once recognize the keys, which were through

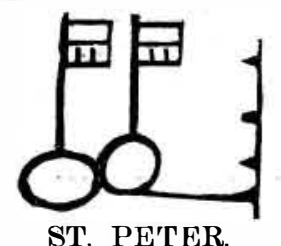

out the middle ages considered as the emblem of St. The next to it is not at first sight so plain. It occurs,
Theter. however, on the day on which St. Lawrence is com for the gridiron; this martyr having been broiled to

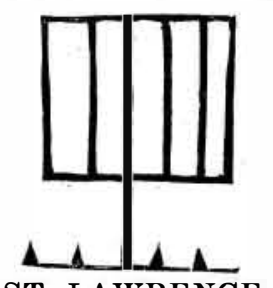

death because he refused to give up the treasure of the church which was be supposed to be in his custody. tended by this to confuse the Welsh Archbishop with tended by this to confuse the Welsh Archbishop with
the holy king, but the similarity of the name was a

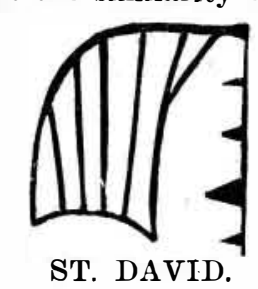

sufficient ground for the use of the well-known emblem Betist's day is distinguished by the figure of a sword, the instrument of his death.

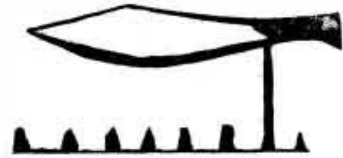

T JOHN THE BAPTIST.

In the same manner we find the hatchet as the em-

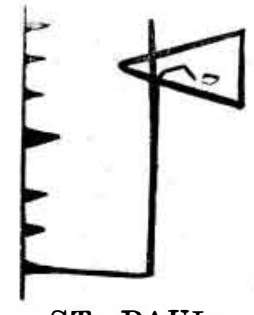

ST. PAUL.

blem of St. Paul, as tradition informs us that he was

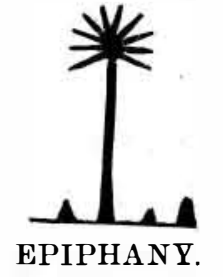

But the next, even when we know that it occurs on St. Swithin's day, is very puzzling. It has been

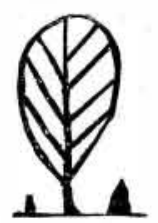

ST. SWITHIN

The last is the emblem of St. Michael. The office of weighing the souls of the good and bad against each
other has been always, in mediæval lore, assigned to

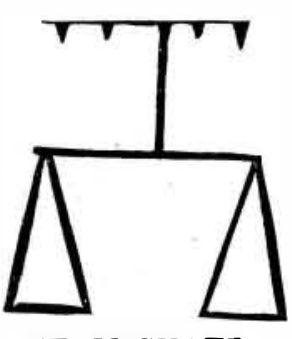

ST. MICHAEL.

this saint; hence the scales are employed in the clog

\section{PHASES OF AMERICAN PROGRESS.}

THE address of Mr. Atkinson, as Vice-President of Section 1 of the American Association for the Advancecognizes the great progress made in material welfare during the past twenty years, both in the production have no right to rest won past achievements have no right to rest upon past achievements. During devoted to the increasing production and the cheaper distribution of food. With free commerce over a larger area and among a greater number"of people than enjoy the same freedom in any other part of the world, it has

1. That nowhere else are the products of labor and of 2. Nowhere else are wages and profits so high

3. Nowhere else is the cost of production measured in 4. Nowhere else are high wages so sure to be the result and reward of a low cost of labor. 5. Nowhere else is so much general benefit derive 6. Nowhere else is so small a part of the public income used for destructive purposes.
Mr. Atkinson refers especially to the increase in railMr. Atkagson refers is partly a result of the Bessemer mode of making steel, and to the extraordinary progress made in securing cheaper transportation. The general use of the screw propeller has resulted in an enormous saving, and likewise the use of agricultural machinery, the opening of oil wells, the invention of aniline colors, the employment of electricity, the development of machine tools, and many other improve-
ments to which he calls attention. Comparative safety ments to which he calls attention. Comparative safety
from loss by fire has been attained by better construction of buildings. Attention is called to the progress already nade in the use of phosphate deposits, and to the opportunity for almost unlimited increase in the use of such deposits at the West, and salt deposits of Canada. In spite of all this, Mr. Atkinson maintains that the average product of the people
does not exceed 50 to 55 cents per day for each person. does not exceed 50 to 55 cents per day for each person.
The progress of invention or machinery has displaced a great number of workers for a time. On the other railroad building has displaced, he maintains, nore than 100,000 persons formerly engaged in such labor. There is enough in the country for all, and yet there is little room for further saving in some directions-in the cost of transportation, for example-while in other directions there is still enormous waste, and especially in Mr. Atkinson urges that the waste land of New Mr. Atkinson urges that the waste land of New
England can probably be employed most profitably by and instances his own experience, stating that he has duct of one acre for five years past. He presents a body of interesting information regarding the use of cotton seed, and the cost of raising cattle with pitted England can yet raise animal food at a less cost than it can eat from its waste land, if the methods he discusses prove feasible. Concerning the value of different articles of food in consumption, Mr. Atkinson present by German scientists, showing the proportions of protein, of fats, and of carbo-hydrogens in the different kinds of food in common us. In the samely employed in this and in of her coun tries, and it is interesting to observe how the natural tastes of the people in many countries have led them to prefer articles of diet which con tain. in large measure or at the least cost, the chemical elements necessary to sustain life and to maintain strength for productive labor. The information on this subject which the ad-
dress presents is too scientific in character for popular 